\title{
An Old Story in New Light: X-Ray Powder Diffraction Provides Novel Insights into a Long-Known Organic Solid-State Rearrangement Reaction
}

\author{
Ivan Halasz, ${ }^{\mathrm{a}, \mathrm{b}, *}$ Nikola Cindro, ${ }^{\mathrm{a}}$ Robert E. Dinnebier, ${ }^{\mathrm{b}}$ and Hrvoj Vančik ${ }^{\mathrm{a}}$ \\ ${ }^{a}$ Department of Chemistry, Faculty of Science, University of Zagreb, Horvatovac 102a,10000 Zagreb, Croatia \\ ${ }^{\mathrm{b}}$ Max-Planck-Institute for Solid State Research, Heisenbergstrasse 1, 70569 Stuttgart, Germany
}

RECEIVED APRIL 25, 2012; REVISED APRIL 9, 2013; ACCEPTED APRIL 18, 2013

\begin{abstract}
The first in situ diffraction study of the long-known solid-state rearrangement of $p$-bromobenzeneazotribenzoylmethane is reported. This proof-of-principle study demonstrates how modern laboratory X-ray powder diffraction, accompanied by up-to-date processing tools, can be used to monitor and describe mechanisms of organic solid-state reactions while it also underpins its necessity for structural characterisation of in situ formed crystalline phases. (doi: 10.5562/cca2127)
\end{abstract}

Keywords: powder diffraction, hot-stage microscopy, solid-state reaction, rearrangement, optical microscopy

\section{INTRODUCTION}

Reactions in molecular crystals are attractive due to their inherently solvent-free, environmentally-friendly and often topochemical nature. ${ }^{1}$ Whereas photochemical rearrangements have received a lot of attention in that respect, ${ }^{1 \mathrm{l}, 2}$ thermochemical processes are significantly less explored. ${ }^{3}$ The first step in elucidating the mechanism of a solid-state reaction is the structural analysis of all participating solid phases. ${ }^{4}$ This could be the major reason why the solid state is extremely rarely considered as the reaction medium by a synthetic chemist, as methods for monitoring solid-state reactions and simultaneously characterizing their products are not as readily available. Thus far, only for a rare class of solid-state reactions which proceed in a single-crystal-to-singlecrystal (SCSC) manner, ${ }^{4,5}$ the structural analysis of solid product phases was possible via single crystal X-ray diffraction. However, vast majority of solid-state reactions yield products in the form of polycrystalline material, which, for the purpose of structural characterization, needs to be removed from the reaction mixture and often recrystallised. From such a routine two major problems arise: (1) intervention trough recrystallisation can lead to different forms of the investigated products (solvates, polymorphs) and (2) quenching to ambient conditions may result in transformation to different phases rendering in situ formed phases unavailable. However, advances in laboratory powder diffraction instrumentation and data processing algorithms give prospects to gain adequate dynamic and structural information also for non-SCSC reactions. ${ }^{6}$ For this reason we chose to reinvestigate, by using present-day in situ time- and temperature-resolved X-ray powder diffraction (XRPD), a solid-state reaction which is long-known and has been thoroughly studied, but using the instrumentation available some 40 years ago.

Thermal rearrangement of benzeneazotribenzoylmethane in solution and in the solid state has been known for over a century. ${ }^{7}$ The solid-state rearrangement of its $p$-bromo derivative (1), which is in the focus in this study, was extensively studied by Curtin, Paul and coworkers, ${ }^{8}$ who identified the formation of two distinct products during the reaction (Scheme 1). ${ }^{8 \mathrm{c}}$ One of the products results from migration of a benzoyl group onto a neighbouring benzoyl group, so as to form an enol benzoate (2). The second product results from migration of the benzoyl group onto the diazo group, forming a benzoylphenylhydrazone (3). Reaction products are formed as polycrystalline materials exhibiting different colours (Scheme 1). Previous reports described that the thermal solid-state rearrangement initially affords both $\mathbf{2}$ and $\mathbf{3}$, but on further heating $\mathbf{3}$ is obtained as the single product. ${ }^{8 \mathrm{c}}$ In an attempt to recrystallise $\mathbf{3}$ to obtain single crystals suitable for structural analysis, it was found that $\mathbf{3}$ exists in two polymorphic forms. ${ }^{8 c}$ Namely, the high-temperature polymorph (3-HT) obtained in the thermal reaction and the low-temperature polymorph (3-LT) obtained by recrystallisation form solution. While 3-LT transforms to 3-HT upon heating,

\footnotetext{
* Author to whom correspondence should be addressed. (E-mail: ihalasz@chem.pmf.hr)
} 


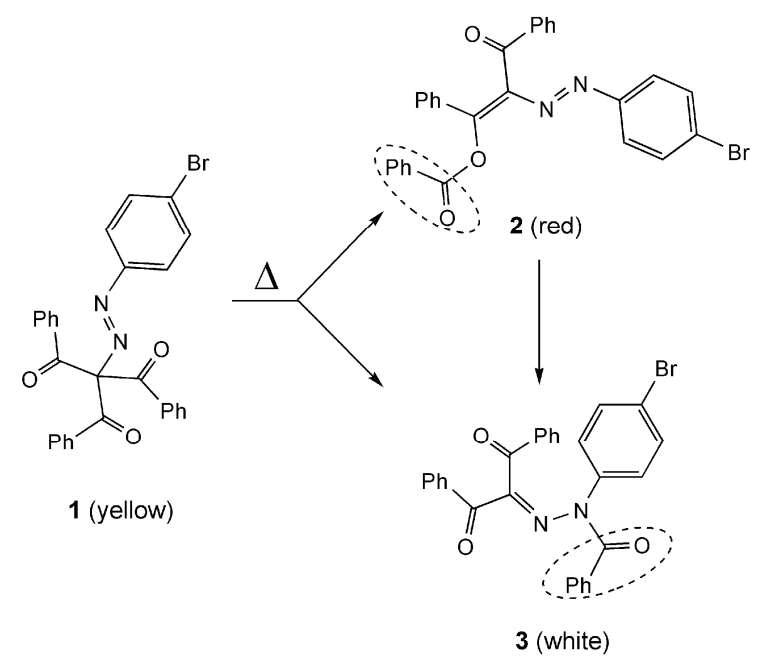

Figure 1. Thermal rearrangement reactions of $\mathbf{1}$. The benzoyl group that has migrated in each product is circled.

cooling does not result in the reverse transformation. ${ }^{8 c}$ Furthermore, even though the crystal structure of the intermediate product $\mathbf{2}$ has been reported, ${ }^{\mathrm{e}}$ diffraction peaks of the intermediate crystalline phase found in this work (see later) cannot be assigned to it. Thus, except for the crystal structure of $1,^{8 \mathrm{c}}$ structures of all other crystalline reaction participants remained unknown. Herein, we demonstrate how XRPD can be employed to monitor the evolution of crystalline phases during the course of a solid-state reaction and subsequently, to structurally characterise the in situ formed reaction products.

\section{EXPERIMENTAL}

\section{Synthesis of $\boldsymbol{p}$-bromobenzeneazotribenzoylmethane (1)}

Benzalacetophenone. Acetophenone (52 g, $0.43 \mathrm{~mol})$ and benzaldehyde ( $46 \mathrm{~g}, 0.43 \mathrm{~mol}$ ) were added into a solution of $\mathrm{NaOH}\left(21.8 \mathrm{~g}, 0.55 \mathrm{~mol} ; 200 \mathrm{~cm}^{3}\right.$ of water and $120 \mathrm{~cm}^{3}$ of ethanol). The solution was stirred for twelve hours with the temperature maintained below $30{ }^{\circ} \mathrm{C}$. The resulting solution was subsequently refrigerated overnight to yield crude crystalline benzalacetophenone. The crystals were filtered under reduced pressure, washed with water, and recrystallised from ethanol (77 g, $85 \%$ yield).

Benzalacetophenone dibromide. Benzalacetophenone $(77 \mathrm{~g}, 0.37 \mathrm{~mol})$ was dissolved in $\mathrm{CCl}_{4}\left(220 \mathrm{~cm}^{3}\right)$ and the obtained solution was cooled in an ice bath. Bromine $\left(19 \mathrm{~cm}^{3}, 0.37 \mathrm{~mol}\right)$ was slowly added to the vigorously stirred solution. Upon reaction completion, the solid dibromide (115 g, $84 \%$ yield) was filtered and washed with hot ethanol $\left(180 \mathrm{~cm}^{3}\right)$.

Dibenzoylmethane (Hdbm). Benzalacetophenone dibromide (100 g, $0.27 \mathrm{~mol}$ ) was dissolved in $\mathrm{MeOH}$ $\left(90 \mathrm{~cm}^{3}\right)$ and placed in a three-necked round-bottomed flask, equipped with a stirrer and a dropping funnel. A solution of sodium methoxide, prepared from $\mathrm{Na}$ (12.5 $\mathrm{g}, 0.54 \mathrm{~mol})$ and absolute methanol $\left(125 \mathrm{~cm}^{3}\right)$, was rapidly added to the stirred benzalacetophenone dibromide solution, and refluxed for one hour. Concentrated solution of $\mathrm{HCl}$ (about $4 \mathrm{~cm}^{3}$ ) was added dropwise until the reaction mixture was neutral. After refluxing for five minutes, $80 \mathrm{~cm}^{3}$ of cold water were added to the reaction mixture, and the flask was cooled in an ice bath. Precipitated white crystals of Hdbm were separated by filtration, washed with cold $\mathrm{MeOH} /$ water $(\varphi=$ $\left.50 \%, 25 \mathrm{~cm}^{3}\right)$ and water, and air-dried $(45-48 \mathrm{~g}, 74-80$ $\%$ yield).

Tribenzoylmethane (Htbm). Hdbm (15 g, 66 mmol) was disolved in $\mathrm{MeOH}\left(100 \mathrm{~cm}^{3}\right)$ with heating, and a solution of $\mathrm{NaOH}(3 \mathrm{~g}, 75 \mathrm{mmol})$ in $\mathrm{MeOH}(50$ $\mathrm{cm}^{3}$ ) was added. The obtained solution was stirred with heating for five minutes. The volume of the solution was reduced to $50 \mathrm{~cm}^{3}$ and refrigerated. The obtained sodium salt of Hdbm (Nadbm) (14.95 g) was filtered under reduced pressure and subsequently dissolved in hot ethyl acetate. While stirring, benzoyl chloride ( $8.5 \mathrm{~g}$, $60 \mathrm{mmol}$ ) was added drop-wise. Htbm separated almost immediately as a white precipitate which was filtered under reduced pressure, and washed with methanol (6.05 g, $28 \%$ yield).

p-Bromobenzeneazotribenzoylmethane $e^{8 \mathrm{c}}(\mathbf{1})$. A solution of tribenzoylmethane $(2.95 \mathrm{~g}, 9 \mathrm{mmol})$ and $\mathrm{K}_{2} \mathrm{CO}_{3}(2.95 \mathrm{~g}, 21 \mathrm{mmol})$ in ethyl acetate $\left(300 \mathrm{~cm}^{3}\right)$ was heated while stirred for 30 minutes, and subsequently extracted with $300 \mathrm{~cm}^{3}$ of water. The ice-cold water solution of potassium tribenzoylmethane (Ktbm) was mixed with an ice-cold solution of $p$-bromobenzenediazonium tetrafluoroborate salt [prepared from $p$-bromoaniline $(2.064 \mathrm{~g}, 12 \mathrm{mmol})$ in $48 \%$ tetrafluoro-boric acid $\left(4.5 \mathrm{~cm}^{3}\right)$ diluted with water $\left(10 \mathrm{~cm}^{3}\right), \mathrm{NaNO}_{2}$ solution $\left(0.91 \mathrm{~g}, 13.2 \mathrm{mmol} ; 5 \mathrm{~cm}^{3} \mathrm{H}_{2} \mathrm{O}\right)$ and $\mathrm{CH}_{3} \mathrm{COO}-\mathrm{Na}$ solution $\left(9.8 \mathrm{~g}, 0.12 \mathrm{~mol} ; 150 \mathrm{~cm}^{3} \mathrm{H}_{2} \mathrm{O}\right.$ ] (important: temperature of any mixture containing diazonium salt must be kept below $5{ }^{\circ} \mathrm{C}$ at all times!). The resulting mixture was stirred for an additional hour, and extracted with $400 \mathrm{~cm}^{3}$ of ether in portions. The combined extracts were dried over sodium sulphate and their volume was reduced to $5 \mathrm{~cm}^{3}$. After cooling to $0{ }^{\circ} \mathrm{C}$, yellow crystals (1.02 g, $16 \%$ yield) were filtered under reduced pressure.

\section{Powder Diffraction}

High-resolution powder X-ray diffraction patterns were collected on a Bruker D8 Advance powder diffractometer, $\mathrm{Cu} K_{\alpha 1}$ radiation from a primary $\mathrm{Ge}(111)$ Johannson monochromator, Våntag-1 position sensitive detector with $6^{\circ}$ angle opening; step mode with $0.0085^{\circ}$ per step; the diffractometer is equipped with a capillary 
furnace; the sample was contained in a $0.5 \mathrm{~mm}$ radius borosilicate glass capillary which was spun during data collection to improve particle statistics. Pattern of the in situ obtained 3 was collected in the angle region from $4^{\circ}$ to $70^{\circ}$ data and the total data collection time was $6 \mathrm{~h}$. Temperature-resolved XRPD measurements have been performed on a laboratory diffractometer described above which is equipped with a capillary furnace (mri Physikalische Geräte GmbH, Karlsruhe, Germany). The sample was contained in a $0.5 \mathrm{~mm}$ borosilicate glass capillary. Data collection of each pattern was set to start after the desired temperature is reached which was held constant during the data collection of each pattern. Heating rate was $0.5^{\circ} \mathrm{C} \mathrm{s}^{-1}$.

\section{RESULTS AND DISCUSSION}

Single crystals of $\mathbf{1}$, grown by evaporation from the acetone/dichloromethane/ether (1/1/1) solvent mixture, were prismatic in shape, dark yellow and transparent. For the visual inspection of the thermal rearrangement reaction via hot-stage microscopy (HSM), large single crystals of $\mathbf{1}$ were selected $(\approx 1 \mathrm{~mm}$ in size $)$ and heated at the rate of 5 $\mathrm{K} \mathrm{min}^{-1}$. The first visual sign of the thermal reaction were cracks that, in almost all cases, appeared within the crystals. Subsequently, the reaction advanced predominantly in the vicinity of cracks (Figure 1). HSM confirmed partial melting during the reaction which was visible as motion of small pockets of liquid. ${ }^{8 \mathrm{~d}, 9}$ Cracks formed anywhere in the crystals of 1 without a preference to any visible defects in the crystals or on their surface. Cracks began to form between 120 to $135{ }^{\circ} \mathrm{C}$. ${ }^{10}$ Upon heating to $140{ }^{\circ} \mathrm{C}$ or above, crystals became opaque and dark red to purple in colour, but retained their initial shape and could be manipulated without disintegration.

One such thermally treated crystal of $\mathbf{1}$ was mounted on a single crystal diffractometer to determine its crystallinity. The diffraction frames exhibited no discrete diffraction maxima, but rather Debye-Scherrer rings that confirmed disintegration of the initial single crystal into a polycrystalline material (Figure 2). Peak positions suggest formation of only the high-temperature white product, 3-HT ${ }^{8 c}$ Considering the red colour of the material, absence of any diffraction peaks that could belong to the red $\mathbf{2}$ is somewhat surprising.

To avoid problems of poor resolution and to verify whether any Bragg peaks of solid 2 appear during the rearrangement reaction, a high-temperature timeresolved experiment was performed using a highresolution X-ray powder diffractometer (TR-XRPD). Single crystals of $\mathbf{1}$ were thus gently crushed in an agate mortar into a fine yellow powder which was packed in a capillary and heated while in situ collecting powder diffraction patterns. Diffraction maxima of 1 diminished and the principal crystalline rearrange-
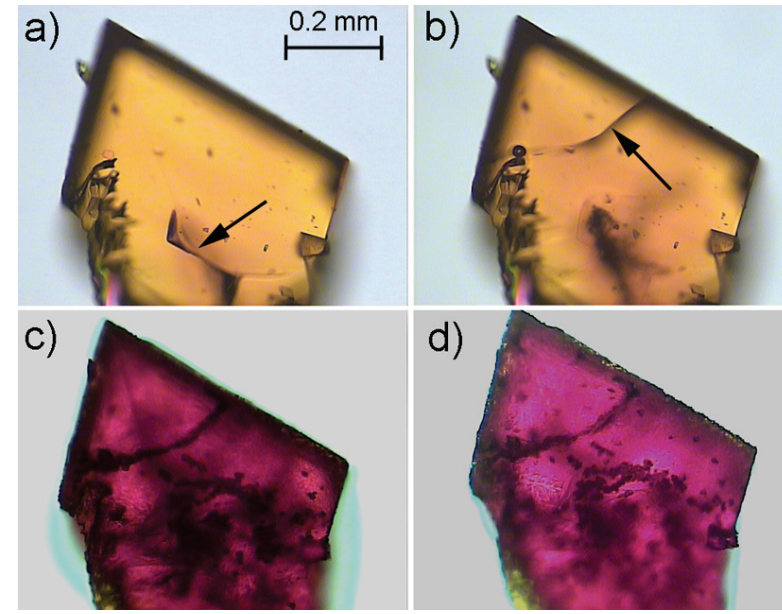

d)

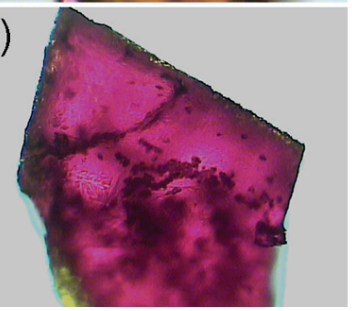

Figure 1. Solid-state rearrangement of $\mathbf{1}$ taking place in a single crystal. The crystal at (a) $130{ }^{\circ} \mathrm{C}$, (b) $132{ }^{\circ} \mathrm{C}$, (c) $139{ }^{\circ} \mathrm{C}$ and (d) $145{ }^{\circ} \mathrm{C}$. Heating rate, $5{ }^{\circ} \mathrm{C} \mathrm{min}{ }^{-1}$. Cracks are indicated by arrows in a) and b).

ment product could clearly be identified as 3-HT (Figure 3). However, another crystalline phase appeared in small amounts during the reaction (Figure 3) but its reflections could not be assigned to the known crystal structure of $2 .{ }^{8 \mathrm{e}}$ Peaks belonging to this phase vanished upon prolonged heating leaving pure 3-HT, in the form of an off-white powder, as the only crystalline product. As pointed out above, crystal structure of 3-HT has thus far remained unknown. With this in

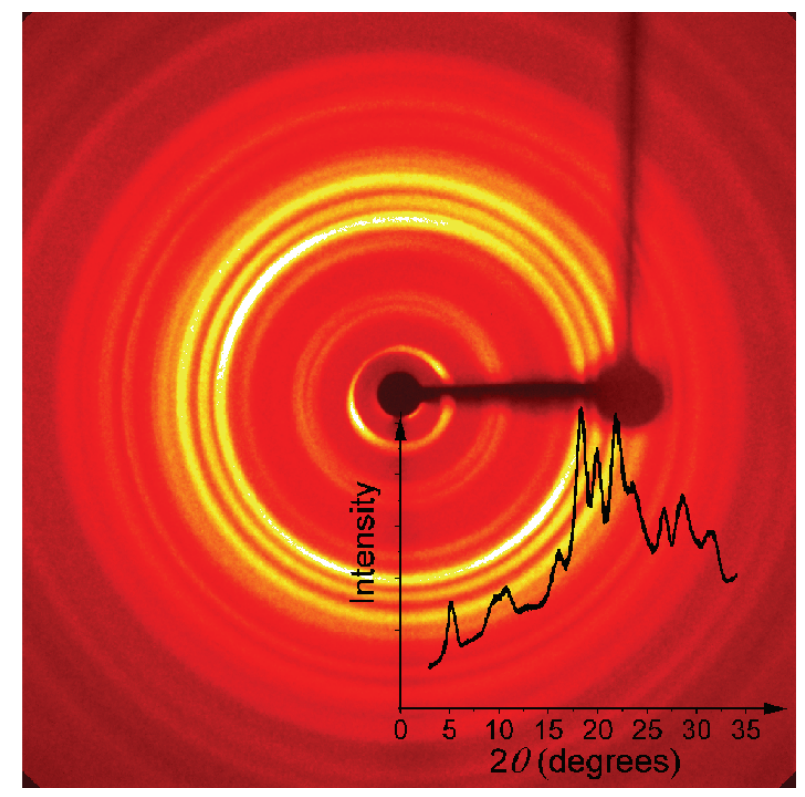

Figure 2. (a) Raw diffraction pattern of the sample obtained by heating the single crystal of 1 at $140{ }^{\circ} \mathrm{C}$ with the extracted diffraction pattern obtained by summation over the DebyeScherrer cones. The shade in the image is caused by two beamstops as the diffractometer had two (molybdenum tube and copper tube) $\mathrm{X}$ ray sources. 


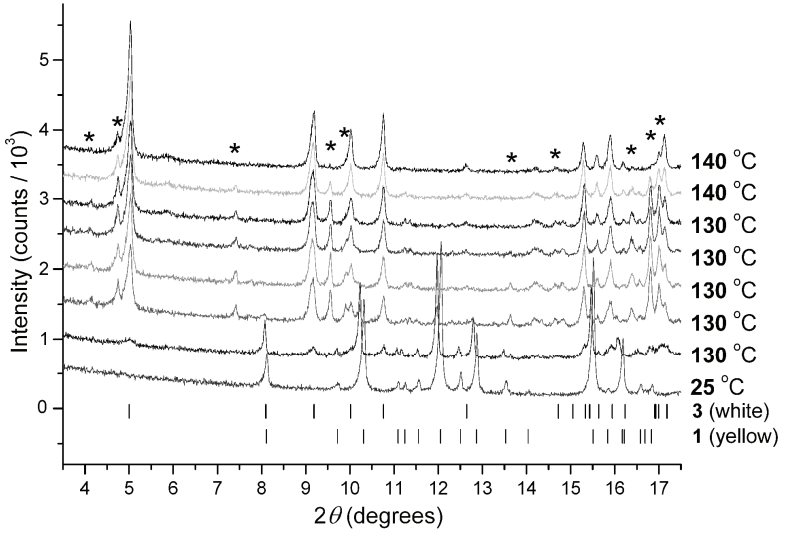

Figure 3. Low-angle region of the time-resolved powder patterns obtained during heating of $\mathbf{1}$. Patterns are separated by $2 \mathrm{~h}$ in time. Reflection position marked with “*” belong to the intermediate crystalline phase. Vertical bars mark calculated reflection positions for $\mathbf{1}$ or $\mathbf{3}$. Shift in peak positions of $\mathbf{1}$ in two lower patterns is due to different data-collection temperatures.

mind, to elucidate its crystal structure, we turned to modern powder diffraction techniques.

A high-resolution powder diffraction pattern of 3-HT was collected on a sample prepared in the previously described experiment. It was indexed using an orthorhombic unit cell which was found by the program DICVOL0 $^{11}$ (Table 1). Likely systematic extinctions suggested the $P 2{ }_{1} 2_{1} 2_{1}$ space group. Crystal structure solution was then attempted by direct space global optimization $^{12}$ assuming the molecular structure given in Scheme 1. Global optimization restrained bond lengths and angles to their expected values, leaving torsion angles free to allow for the correct conformation to be found. The most likely structural model was selected based on chemical reasoning (reasonable conformation,

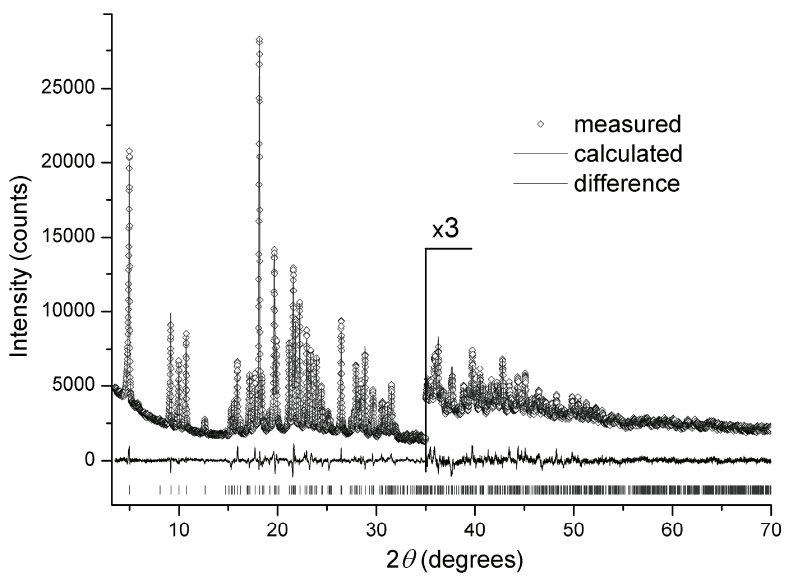

Figure 4. Final Rietveld refinement plot for 3 . To reveal more details, the high angle region is scaled by a factor of 3 . Vertical ticks represent calculated reflection positions.
Table 1. Crystallographic and Rietveld refinement data for 3

\begin{tabular}{|c|c|}
\hline Compound & 3 \\
\hline Molecular formula & $\mathrm{C}_{28} \mathrm{H}_{19} \mathrm{~N}_{2} \mathrm{O}_{3} \mathrm{Br}$ \\
\hline Formula weight (in $\mathrm{g} / \mathrm{mol}$ ) & 511.39 \\
\hline Space group & $P 2_{1} 2_{1} 2_{1}$ \\
\hline$Z$ & 4 \\
\hline$a / \AA$ & $35.2904(8)$ \\
\hline$b / \AA$ & $11.4742(2)$ \\
\hline$c / \AA$ & $5.8528(1)$ \\
\hline$V / \AA^{3}$ & $2369.95(8)$ \\
\hline Temperature (K) & 293 \\
\hline$\rho($ calc. $) /\left(\mathrm{g} \mathrm{cm}^{-3}\right)$ & 1.433 \\
\hline Wavelength $(\AA)$ & 1.54056 \\
\hline$R-\exp (\%)^{(\mathrm{a})}$ & 2.22 \\
\hline$R-\mathrm{p}(\%)^{(\mathrm{a})}$ & 3.61 \\
\hline$R$-wp (\%) ${ }^{(\mathrm{a})}$ & 4.48 \\
\hline$R-F^{2}(\%)^{(\mathrm{a})}$ & 2.66 \\
\hline $\mathrm{GOF}^{(\mathrm{a})}$ & 2.20 \\
\hline Starting angle $\left({ }^{\circ} 2 \theta\right)$ & 3 \\
\hline Final angle $\left({ }^{\circ} 2 \theta\right)$ & 70 \\
\hline Step width $\left({ }^{\circ} 2 \theta\right)$ & 0.0085 \\
\hline Time/scan (hr) & 6 \\
\hline No. of variables & 219 \\
\hline
\end{tabular}

(a) as defined in Topas, version 4.1 (Topas 4 Technical Reference, Bruker-AXS, Karlsruhe, Germany)

absence of too close contacts) and introduced into Rietveld refinement which was accomplished using the program Topas ${ }^{13}$ (Figure 4). The structure model was refined with the molecular geometry restrained to expected values. The two polymorphic crystal structures are both sustained only by weak van der Waals-type interactions with the major difference in molecular conformations being the orientation of the phenyl ring of the migrated benzoyl group (Figure 5).

We also aimed to solve the crystal structure of the intermediate solid phase in order to further clarify the solid-state rearrangement mechanism of $\mathbf{1} \rightarrow \mathbf{3}$. Thus, we attempted to isolate the intermediate phase from the reaction mixture of partially reacted $\mathbf{1}$. Unfortunately, all attempts to separate the mixture by column chromatography failed (i.e. this phase could be isolated only as a bright red powder containing small amounts of 3-LT). This intermediate also could not be characterised on the basis of the previously solved crystal structure of $\mathbf{2}$ but, importantly, its diffraction pattern corresponded to the vanishing peaks as observed during heating of $\mathbf{1}$. When subjected to a high-temperature time-resolved XRPD experiment, this solid yielded 3-HT as the only crystalline product.

In order to follow this rearrangement reaction at the molecular level, we have performed the time-resolved 


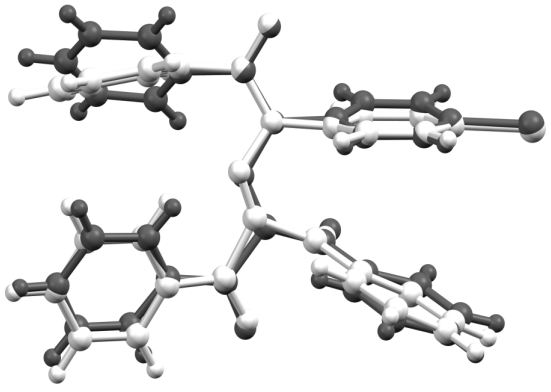

Figure 5. Comparison of molecular conformations of $\mathbf{3}$ in the two polymorphs. Color code: dark grey $-\mathbf{3}-\mathbf{L T}^{8 \mathrm{e}}$ and light grey $-\mathbf{3 - H T}$. The migrated benzoyl group shows the biggest difference in conformation.

infrared spectroscopy experiment during heating of $\mathbf{1}$ at $140{ }^{\circ} \mathrm{C}$ which were in accordance with $\mathbf{2}$ is the intermediate structure. The band that could be assigned to the carbonyl stretching of the ester group of $\mathbf{2}$ was observed to form almost immediately at $1749 \mathrm{~cm}^{-1}$ and disappeared upon prolonged heating. The shoulder at $1643 \mathrm{~cm}^{-1}$,
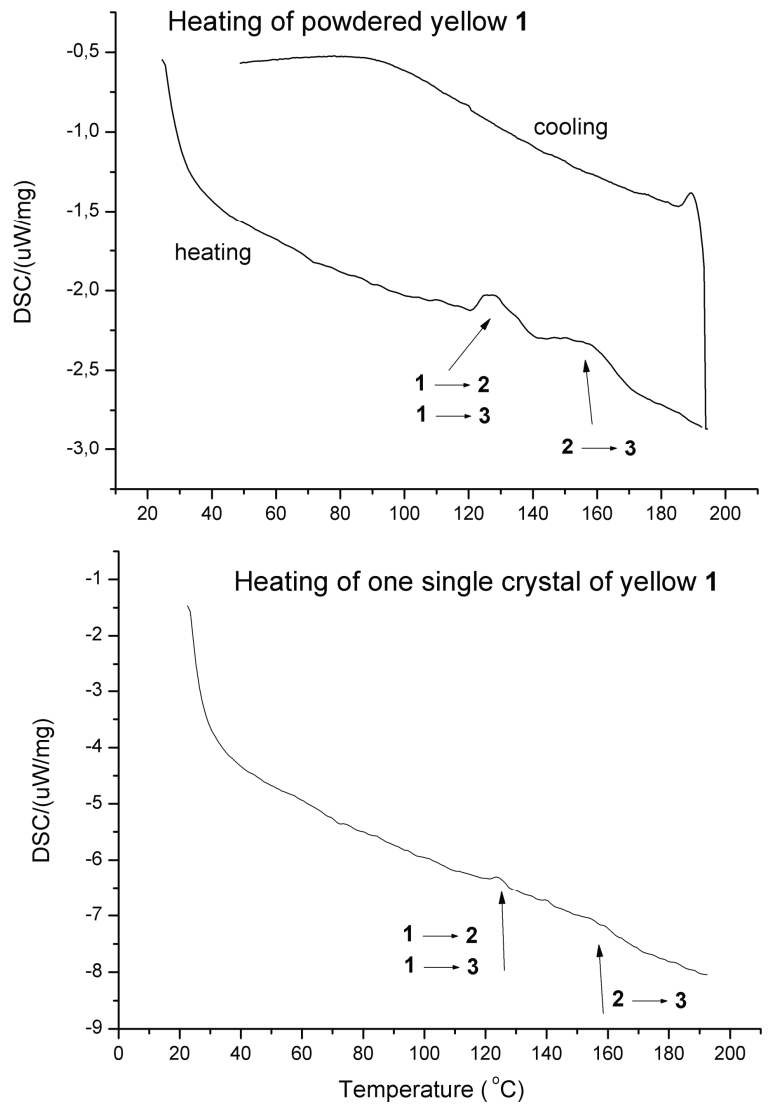

Figure 6. DSC measurements of yellow one (above) powdered sample and (below) one single crystal as they were used in hot-stage microscopy experiments. Exothermal events have maxima. Samples were heated in an argon atmosphere at the rate of $5{ }^{\circ} \mathrm{C} \mathrm{min}^{-1}$. which grew in intensity during the whole heating, is assigned to $\mathrm{C}=\mathrm{N}$ stretching of $\mathbf{3}$. The disappearing band at $1493 \mathrm{~cm}^{-1}$ is assigned to the stretching of the azo group present in $\mathbf{1}$ and $\mathbf{2}$ but absent in $\mathbf{3}$ while the increasing band at $1683 \mathrm{~cm}^{-1}$ is assigned to $\mathrm{C}-\mathrm{N}$ stretching of the amide group of $\mathbf{3}$. Thus, the bands belonging to the intermediate phase appear simultaneously with bands belonging to $\mathbf{3}$ and disappear upon further heating when $\mathbf{3}$ is formed as the single rearrangement product. These results provided evidence in support of simultaneous rearrangements $\mathbf{1} \rightarrow \mathbf{2}$ and $\mathbf{1} \rightarrow \mathbf{3}$ as well as rearrangement $\mathbf{2} \rightarrow \mathbf{3}$. The differential scanning experiment (Figure 6) is interpreted according to diffraction and spectroscopy results.

\section{CONSLUSION}

We have applied time- and temperature-resolved in situ $\mathrm{X}$-ray powder diffraction and infrared spectroscopy to reveal interconversions among the crystalline phases and to gain insight into dynamics of the long-known solid-state thermal rearrangement of 1 . During the study, we have used high-resolution XRPD to elucidate and structurally characterise the in situ obtained polymorph of 3. The studies presented herein reveal conclusively that the unknown intermediate crystalline phase is formed which probably corresponds to $\mathbf{2}$ and that it also undergoes a thermal rearrangement reaction.

To expand the use of the solid-state as a reaction medium by a synthetic organic chemist, better understanding of solid-state reactions must be accompanied by easier and faster methods of analysis. ${ }^{2}$ We find advanced XRPD techniques, along with recent laboratory instrumentation which also allows time-resolved measurements at non-ambient conditions, to be one such tool which is indeed becoming increasingly efficient and user-friendly and should receive a more wide-spread use in analysis of solid-state reactions. ${ }^{14,15}$ Furthermore, XRPD is essential for structural analysis where the in situ obtained solid forms, as was in the case described herein, differ from the forms attainable by other means of crystallisation or quenching.

Supplementary Materials. - CCDC 746471 contains crystallographic data of 3. These data can be obtained free of charge upon request from the Cambridge Crystallographic Data Centre via www.ccdc.cam.ac.uk/data_request/cif.

Acknowledgements. The authors are grateful for the financial support of the Ministry of Science, Education and Sports of Croatia (Grant No. 119-1191342-1334), the Bundesministerium für Bildung und Forschung (BMBF) and the Fonds der Chemischen Industrie (FCI). Edislav Lekšić is acknowledged for help with the hot-stage microscopy. We are grateful to Dr. Dejan-Krešimir Bučar, Dr. Mirta Rubčić, Dr. Krunoslav Užarević, Prof. Tomislav Friščić and Dr. Ivica Đilović for fruitful discussions. 


\section{REFERENCES}

1. (a) K. Tanaka and F. Toda, Chem. Rev. 100 (2000) 1025-1074; (b) V. Ramamurthy and K. Venkatesan, Chem. Rev. 87 (1987) 433-481; (c) G. Kaupp, Top. Curr. Chem. 254 (2005) 95-183; (d) F. Toda, Top. Curr. Chem. 254 (2005) 1-40; (e) K. Cheng and B. M. Foxman, J. Am. Chem. Soc. 99 (1977) 8102-8103; (f) J. J. Vittal, Coord. Chem Rev. 251 (2007) 1781-1795; (g) D. Braga, and F. Grepioni, Angew. Chem. Int. Ed. 43 (2004) 40024011; (h) J. W. Lauher, F. W. Fowler, and N. S. Goroff, Acc. Chem. Res. 41 (2008) 1215-1229; (i) J. M. Thomas, Pure Appl. Chem. 51 (1979) 1065-1082; (j) G. R. Desiraju, Solid State Ionics (1997) 839-842; (k) T. Friščić, J. Mater. Chem. 20 (2010) 7599-7605; (l) T. Praveen, U. Samanta, T. Das, M. S. Shashidhar, and P. Chakrabarti, J. Am. Chem. Soc. 120 (1998) 3842-3845; (m) J. M. Thomas, Phil. Trans. Royal Soc. Lond. A 277 (1974) 251-286.

2. (a) A. E. Keating and M. A. Garcia-Garibay, Photochemical Solid-to-Solid Reactions in: V. Ramamurthy and K. Schanze (Eds.), Molecular and Supramolecular Photochemistry, Vol. 2, MarcelDekker, New York, 1998, pp. 195-248; (b) L. R. MacGillivray, G. S. Papaefstathiou, T. Friščić, T. D. Hamilton, D.-K. Bučar, Q. Chu, D. B. Varshney, and I. G. Georgiev, Acc. Chem. Res. 41 (2008) 280-291; (c) J. R. Scheffer and W. Xia, Top. Curr. Chem. 254 (2005) 233-262; (d) M. Nagarathinam, A. M. P. Peedikakkal, and J. J. Vittal, Chem. Commun. (2008) 52775288; (e) M. D. Cohen, Tetrahedron 43 (1987) 1211-1224; (f) G. M. J. Schmidt, Pure Appl. Chem. 27 (1971) 647-678. (g) W. Jones, H. Nakanishi, C. R. Theocharis, and J. M. Thomas, J. Chem. Soc., Chem. Commun. (1980) 610-612; (h) M. J. E. Resendiz, J. Taing, and M. A. Garcia-Garibay, Org. Lett. 9 (2007) 4351-4354; (i) M. Hasegawa, Chem. Rev. 83 (1983) 507518; (j) R. C. Grove, S. H. Malehorn, M. E. Breen, and K. A. Wheeler, Chem. Commun. 46 (2010) 7322-7324.

3. (a) I. C. Paul and D. Y. Curtin, Acc. Chem. Res. 6 (1973) 217 225; (b) J. D. Dunitz, Acta Cryst. B51 (1995) 619-631.

4. (a) T. Friščić and L. R. MacGillivray, Aust. J. Chem. 59 (2006) 613-616; (b) A. Natarajan. C. K. Tsai, S. I. Khan, P. McCarren, K. N. Houk, and M. A. Garcia-Garibay, J. Am. Chem. Soc. 129 (2007) 9846-9847; (c) C. Murali, M. S. Shashidhar, R. G. Gonnade, and M. M. Bhadbhade, Chem. Eur. J. 15 (2009) 261-269.

5. (a) I. Halasz, Cryst. Growth Des. 10 (2010) 2817-2823. (b) T. Friščić, and L. R. MacGillivray, Z. Kristallogr. 220 (2005) 351-
363; (c) G. J. Halder, C. J. Kepert, Aust. J. Chem. 59 (2006) $597-$ 604; (d) M. A. Garcia-Garibay, Angew. Chem. Int. Ed. 46 (2007) 8945-8946.

6. (a) F. Guo, J. Marti-Rujas, Z. Pan, C. E. Hughes, and K. D. M. Harris, J. Phys. Chem. C 112 (2008) 19793-19796; (b) M. Rubčić, K. Užarević, I. Halasz, N. Bregović, M. Mališ, I. Đilović, Z. Kokan, R. S. Stein, R. E. Dinnebier, and V. Tomišić, Chem. Eur. J. 18 (2012) 5620-5631.

7. (a) O. Dimroth and M. Hattmann, Ber. 40 (1907) 4460-4465; (b) O. Dimroth and M. Hartmann, Ber. 41 (1909) 4012-4028.

8. (a) D. Y. Curtin and M. L. Poutsma, J. Am. Chem. Soc. 84 (1962) 4887-4892; (b) D. Y. Curtin and M. L. Poutsma, J. Am. Chem. Soc. 84 (1962) 4892-4899; (c) R. T. Puckett, C. E. Pfluger, and D. Y. Curtin, J. Am. Chem. Soc. 88 (1966) 4637-4642; (d) D. Y. Curtin, S. R. Byrn, and D. B. Pendergrass, Jr., J. Org. Chem. 34 (1969) 3345-3349; (e) D. B. Pendergrass, Jr., D. Y. Curtin, and I. C. Paul, J. Am. Chem. Soc. 94 (1972) 8722-8730; (f) D. B. Pendergrass, Jr., D. Y. Curtin, and I. C. Paul, J. Am. Chem. Soc. 94 (1972) 8730-8737.

9. Partial melting was also evidenced when bulk powdered 1 was heated in a Petri dish as a sticky solid was formed.

10. To rule out uneven heating of the crystal as a possible cause of cracking, another set of crystals of 1 were slowly heated $(1 \mathrm{~K}$ $\min ^{-1}$ ), keeping the hot stage and the crystals closer to thermal equilibration. These HSM experiments also revealed crystal cracking in the same temperature range as previously observed. Therefore, we ascribe the crystal cracking to the strain accumulated due to the thermal rearrangement reaction.

11. D. Lauër and A. Boultif, J. Appl. Cryst. 37 (2004) 724-731.

12. V. Favre-Nicolin and R. Cerný, J. Appl. Cryst. 35 (2002) 734-743.

13. Topas, version 4.1 Bruker-AXS, Karlsruhe, Germany.

14. (a) K. D. M. Harris, M. Tremayne, and B. M. Kariuki, Angew Chem. Int. Ed. 40 (2001) 1626-1651; (b) S. Karki. L. Fábián, T. Friščić, and W. Jones, Org. Lett. 9 (2007) 3133-3136; (c) W. I. F. David, and K. Shankland, Acta Cryst. A64 (2008) 52-64; (d) C. W. Padgett, H. D. Arman, and W. T. Pennington, Cryst. Growth Des. 7 (2007) 367-372; (e) M. Kawano, T. Haneda, D. Hashizume, F. Izumi, and M. Fujita, Angew. Chem. Int. Ed. 47 (2008) 1269-1271; (f) I. Halasz and R. E. Dinnebier, J. Pharm. Sci. 99 (2010) 871-878.

15. (a) K. Fujii, Y. Ashida, H. Uekusa, S. Hirano, S. Toyota, F. Toda, Z. Pan, and K. D. M. Harris, Cryst. Growth Des. 9 (2009) 1201-1207; (b) A. Neels, D. Gonzalez Mantero, and H. StoeckliEvans, Cryst. Growth Des. 8 (2008) 1147-1153. 